\title{
Lessons of the month 5: Cardiac tamponade after an acute myocardial infarction: the clinical diagnosis $\mathbf{s}^{*}=$
}

\author{
Authors: Nida Ahmed, ${ }^{A}$ Sabahat Ahmed ${ }^{B}$ and Hazem Lashin ${ }^{\mathrm{C}}$
}

\begin{abstract}
We present the case of a late presenting ST-elevation myocardial infarction with a coronary dissection. After primary percutaneous coronary intervention, the patient went on to develop pericardial effusion with tamponade. Despite only a small volume of fluid, we demonstrate how it can have significant clinical consequences in the diseased heart. We also highlight the value of being able to carry out bedside echocardiography in the acutely unwell post-myocardial infarction patient.
\end{abstract}

KEYWORDS: Tamponade, myocardial infarction, coronary dissection, primary percutaneous coronary intervention

DOI: 10.7861/clinmed.2019-0248

\section{Case presentation}

A 57-year-old man presented with chest pain, having attended multiple times at his local emergency department for the same reason.

His past medical history included bicuspid aortic valve with moderate aortic stenosis, severe left ventricular systolic dysfunction, hypertension and iron deficiency anaemia. Cardiac risk factors also included type 2 diabetes mellitus diagnosed 15 years ago, managed with oral antidiabetics (metformin and linagliptin), as a consequence he also suffered from maculopathy.

The patient was admitted to the heart attack centre as a latepresenting ST-elevation myocardial infarction (STEMI) which was treated with primary percutaneous coronary intervention (PCI) to proximal left anterior descending ( $L A D$ ) vessel. At the time, he was also found to have a $L A D$ dissection requiring angioplasty to this lesion.

During his immediate recovery period post-PCI, he became hypotensive with evidence of shock, admitted to the intensive care unit (ICU) and beside echocardiography was performed by the attending intensivist which revealed poor left ventricular systolic function and a $0.8 \mathrm{~cm}$ pericardial effusion, there was a suspicion of right ventricular free wall compression without significant

Authors: ${ }^{\mathrm{A}}$ core medical trainee year 2, Barts Health NHS Trust, London, UK; ${ }^{\mathrm{B}}$ medical student, GKT School of Medical Education, London, UK; ' Consultant intensivist, Barts Health NHS Trust, London, UK

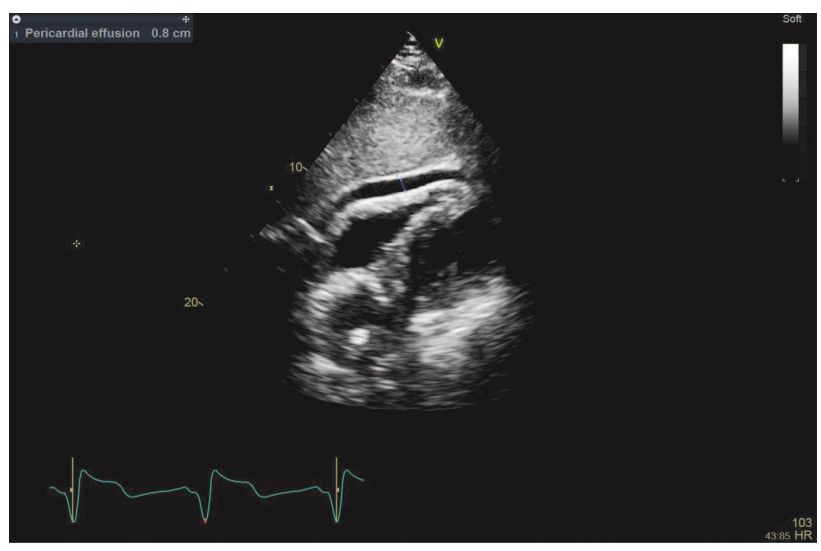

Fig 1. Bedside echocardiography showing poor left ventricular systolic function and a $0.8 \mathrm{~cm}$ pericardial effusion.

tricuspid flow variation or pulsus paradoxus (Fig 1). Though he was requiring inotropes and vasopressors, a pericardial drain was not inserted as the effusion was felt to be of insignificance and the hypotension was deemed to be due to the intrinsic cardiac insult. He subsequently decompensated further with pulsus paradoxus and repeat beside echocardiography showed that the maximum depth of the effusion was now $1.3 \mathrm{~cm}$ around the right ventricle free wall. Urgent pericardiocentesis was performed and a pericardial drain was inserted at the bedside on ICU with inotropes and an intra-aortic balloon pump. After this, he became haemodynamically stable, was successfully weaned off inotropes and remained asymptomatic. The pericardial drain was successfully removed after 5 days and he was safely discharge home.

\section{Discussion}

Pericardial effusion and subsequent cardiac tamponade are recognised as infrequent complications of a STEMI causing haemodynamic instability; one case series recognised the need for emergency physicians, intensivist and cardiologist to be vigilant for this differential in the hypotensive acute-STEMI patient. ${ }^{1}$ Coronary perforation is an uncommon procedural complication of PCI with a prevalence of $0.2-0.6 \%$ though its incidence has decreased over the last couple of decades, it is associated with higher rates of pericardial tamponade, cardiogenic shock and mortality. ${ }^{2-4}$ 
This case demonstrates the importance of recognising cardiac tamponade as a clinical diagnosis; indeed, here we describe how a small amount of additional pericardial fluid can cause decompensation in those with enlarged or poor left ventricle. Cardiac tamponade is associated with worse clinical outcomes at 30-day and 1-year follow-up. ${ }^{5}$

While the first echocardiography was of a bedside standard, it nevertheless recognised the cause of the shock. Therefore, we recognise this as a powerful tool in the arsenal of those working in acute, emergency and intensive care medicine. Courses such as the Focused Echocardiography in Emergency Life Support (FEELS) course organised by the Resuscitation Council or the Focused Intensive Care Echocardiography (FICE) course organised by the Intensive Care Society (other courses also available) occur frequently for healthcare professionals of varying grades looking to upskill.

\section{References}

1 Agrawal A, Zabad MN, Dayanand S, Lygouris G, Witzke C. Pericardium: the forgotten space during acute myocardial infarction. J Emerg Med 2018;55:e85-91.
2 Simsek EC, Kiris T, Emren SV. Management and outcomes of coronary artery perforation during routine percutaneous coronary intervention without advanced procedure: a single-centre report. Am J Cardiol 2018;121:e71.

3 Figueras J, Barrabés JA, Lidón RM et al. Predictors of moderateto-severe pericardial effusion, cardiac tamponade, and electromechanical dissociation in patients with ST-elevation myocardial infarction. Am J Cardiol 2014;113:1291-6.

4 Shaukat A, Sandoval Y, Stanberry L et al. Incidence, predictors, characteristics, management and outcomes of coronary perforations. J Am Coll Cardiol 2018;71(11 Supplement):A1189.

5 Lee WC, Fang HY, Wu C]. Clinical outcomes following covered stent for the treatment of coronary artery perforation. J Am Coll Cardiol 2017;69(16 Supplement):S39.

Address for correspondence: Dr Nida Ahmed, The Roya London Hospital, Whitechapel Rd, London E1 1BB, UK. Email: nida_3683@hotmail.com

\section{Consent and confidentiality in genomic medicine}

\section{Genetic or genomic tests are increasingly used in everyday medical practice. Every clinical field will encounter such tests to a greater or lesser extent.}

\begin{abstract}
Published in 2019, this third edition by the Joint Committee on Genomics in Medicine provides updated guidance on the use of genetic and genomic information in the clinic. Health professionals from all areas of medicine need to know and understand how consent and confidentiality issues may arise, and to understand the potential ways in which the use of genomic tests may change the nature of the relationship between healthcare professionals and patients.
\end{abstract}

Download the guidance at: www.rcplondon.ac.uk/consent-confidentiality-genomic-medicine

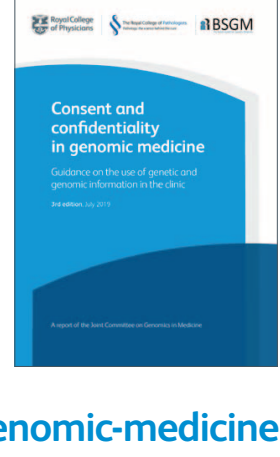

